\title{
Peningkatan Kemampuan Seni Menyanyi Menggunakan Alat Musik Sederhana Pada Anak Kelompok B Melalui Metode Demontrasi
}

\author{
Dwi Agsriyani \\ TK Kartini III Surakarta, Indonesia \\ dwiagsriyani98321@gmail.com
}

\begin{abstract}
This study aims to improve learning outcomes for the ability to sing using simple musical instruments through demonstration methods for group B children in TK Katini III Surakarta. The subjects of this study were 20 children in TK Kartini III Surakarta. The object of this research was the children of group B TK Kartini III who took learning singing skills in the second semester. This type of research is a classroom action research consisting of two cycles, each cycle consisting of planning, implementing, observing and reflecting. The data collection instruments used observation, documentation, questionnaires and direct singing practice tests with musical instruments from used bottles. The results showed that there was an increase in the percentage of completing group B children in the pre-cycle by $38 \%$ (8 children), in the first cycle of $53 \%$ (11 children) in the second cycle the percentage of completeness of children increased to $83 \%$ (16 children). The conclusion of the findings of this study is that the demonstration method can improve learning outcomes using simple musical instruments can improve the learning outcomes of group B children singing skills in TK Kartini III Surakarta Academic Year 2020/2021.

Keywords: Art; Sing; Skills; Simple Musical Instruments
\end{abstract}

\section{ABSTRAK}

Penelitian ini bertujuan untuk meningkatkan hasil belajar kemampuan seni menyanyi menggunakan alat musik sederhana melalui metode demonstrasi pada anak kelompok B di TK Katini III Surakarta. Subyek penelitian ini adalah di TK Kartini III Surakarta yang berjumlah 20 anak.Objek penelitian ini adalah anak kelompok B TK Kartini III yang mengambil pembelajaran keterampilan menyanyi pada semester dua Jenis penelitian ini yaitu penelitian tindakan kelas yang tediri dari dua siklus ,setiap siklus terdiri dari perencanaan ,pelaksanaan, obserrvasi dan refleksi. Instrumen pengumpulan data menggunakan observasi, dokumentasi, angket dan tes praktik menyayi dengan alat music dari botol bekas secara langsung. Hasil penelitian menunjukkan bahwa terjadi peningkatanpresentase penuntasan anak kelompok B pada prasiklus sebesar $38 \%$ ( 8 anak ),pada siklus I sebesar $53 \%(11$ anak ) pada siklus kedua presentase ketuntasan anak meningkat menjadi 83\%(16 anak ). Kesimpulan temuan penelitian ini bahwa metode demonstrasi dapat meningkatkan hasil pembelajaran menggunakan alat musik sederhana dapat meningkatkan hasil belajar keterampilan menyanyi anak kelompok B di TK Kartini III Surakarta Tahun Pelajaran 2020/2021

Kata Kunci: Seni; Menyanyi; Keterampilan; Alat Musik Sederhana

$$
\text { Submitted May 02, } 2021 \text { | Revised May 19, } 2021 \text { | Accepted May 21, } 2021
$$

\section{Pendahuluan}

Pembelajaran adalah proses interaksi peserta didik dengan pendidik dan sumber belajar pada suatu lingkungan belajar (Darmuki dkk., 2017; Darmuki dkk., 2018; Darmuki dkk., 2019). Pembelajaran merupakan bantuan yang diberikan pendidik agar dapat terjadi proses pemerolehan ilmu dan pengetahuan, penguasaan kemahiran dan tabiat, serta pembentukan sikap dan kepercayaan pada peserta didik (Darmuki \& Hidayati, 2019; Darmuki \& Hariyadi, 2019). Hal ini sesuai dengan pernyataan Hidayati \& Darmuki (2021) yang mengemukakan bahwa pembelajaran adalah suatu persiapan yang dipersiapkan oleh guru guna menarik dan memberi informasi kepada siswa, sehingga dengan persiapan yang dirancang oleh guru dapat membantu siswa dalam mencapai tujuan pembelajaran. Belajar adalah suatu proses perubahan tingkah laku akibat dari pengalaman (Darmuki, 2020). Belajar merupakan suatu proses perubahan tingkah laku yang membutuhkan dorongan atau motivasi untuk menggerakkan ke arah lebih baik, dari tidak bisa menjadi bisa, dari tidak tahu menjadi tahu (Darmuki dkk., 2017: 45). Perubahan tingkah laku tersebut bisa berupa dari aspek kognitif, afektif, maupun psikomotorik 
(Darmuki, et al, 2017: 76). Belajar juga dapat didefinisikan sebuah proses dimana tingkah laku ditimbulkan/berubah melalui latihan dan pengalaman (Hariyadi \& Darmuki, 2019: 282). Mengajar adalah menanamkan pengetahuan pada peserta didik untuk mencapai tujuan yang telah ditetapkan (Darmuki \& Hidayati, 2019: 122). Tujuannya adalah penguasaan pengetahuan, keteterampilan dan pemahaman oleh peserta didik.

Pendidikan Anak Usia Dini (PAUD) merupakan pendidikan yang paling mendasar dan penting serta menempati posisi yang sangat strategis dalam pengembangan sumber daya manusia Indonesia (Depdiknas, 20051). PAUD merupakan salah satu upaya pembinaan yang ditujukan kepada anak sejak lahir sampai dengan usia enam tahun, yang dilakukan melalui pemberian rangsangan pendidikan untuk membantu pertumbuhan dan perkembangan jasmani dan rohani agar anak memiliki kesiapan dalam memasuki pendidikan lebih lanjut. Adapaun melalui pendidikan anak usia dini akan membantu merangsang perkembangan otak anak di masa emasnya yaitu umur 3 tahun.

Usia dini merupakan masa dimana anak berada diperiode sensitif yang artinya dimasa inilah anak dengan mudah dapat menerima berbagai stimulus dalam lingkungannya.Pada masa naka usia dini merupakn masa keemasan disepanjang masa rentang usia perkembangan manusia .Itulah mengapa para ahli pendidikan anak memendang usia dini merupakan masa emas ( the golden age)karena tidak dapat diulangdan hanya datang sekali dalam sepanjang usia (Gunarti, 2008). Kemampuan mengekspresikan bentuk kegiatan seni dengan alat musik sederhana kegiatan merupakan utama kecerdassan musikal.

Lwin, dkk. (2008) mengemukakan bahwa musik merupakan aspek pertama yang harus dikembangkan dari sudut neurologis. Karena sejak dari dalam kandungan janin sudah bisa mendengarkan suara-suara termasuk juga musik. Dari semua kecerdasan yang ada dalam diri seseorang, musik memberikan pengaruh terbesar untuk diri manusia dan bisa mengembangkan kecerdasan lainnya. Sehingga aspek kecerdasan musik pada anak sangat penting untuk dikembangkan agar kecerdasan yang lainnnya bisa berkembang dengan baik.

Menurut Sousa (2012) musik memberikan efek yang kuat pada otak dengan cara menstimulasi intelektual dan emosional. Musik juga dapat mempengaruhi tubuh dengan cara mengubah kecepatam detak jantung, kecepatan bernapas, tekanan darah, ambang batas rasa sakit, dan gerakan otot. Berbagai respon tersebut dihasilkan dari aktivitasi jaringan-jaringan saraf yang terlibat dalam motivasi dan rasa senang. Oleh karena itu, untuk perkembangan anak usia dini yang lebih baik perlu mengembangkan aspek kecerdasan musikalnya terlebih dahulu. Penting bagi pendidik atau orang tua untuk mengetahui manfaat kecerdasan musikal pada anak agar keterampilan-keterampilan yang lain dapat berkembang optimal.

Pembelajaran musik merupakan proses interaksi yang terjadi antara pendidik dan peserta didik dalam suatu lingkungan belajar untuk meningkatkan dan mengembangkan potensi rasa keindahan yang dimiliki siswa melalui pengalaman dan penghayatan musik metode demonstrasi merupakan solusi alternatif untu meningkatkan kegiatan pembelajaran (Widia, 2015).

Bernyanyi juga berpengaruh sangat besar bagi seorang anak. Anak-anak tidak perduli apakah lagu itu indah melodinya, bagus harmoninya, cocok kata-katanya, semuanya mereka lahap (Suardika, 2018). Oleh karena itu, peran gurulah untuk mengarahkan anak-anak dalam memperkenalkan lagu-lagu yang baik, cocok untuk anak-anak, mudah dipahami dan memilih lagu yang semangat, disukai anak-anak yang berhubungan dengan sifat pengalaman anak. Apalagi jika lagu tersebut dinyanyikan oleh anakanak seusianya dan diikuti dengan gerakan-gerakan tubuh yang sederhana dapat dirasakan bersamasama akan semakin mudah anak belajar menyadari tubuhnya sendiri, untuk merasakan setara dengan hakikat dalam dirinya sendiri.

Berdasarkan pengamatan yang dilakukan oleh peneliti pada kelompok B Kartini III Surakarta bahwa masih banyak anak yang kemampuan bernyanyinya belum maksimal, hal ini terjadi karena masih sedikitnya alat bantu/media yang digunakan oleh pendidik untuk menstimulan anak-anak agar lebih 
semangat dalam bernyanyi. Selain itu masih banyak anak yang merasa malu dan takut ketika guru menyuruh maju untuk bernyanyi.

Selain itu, dengan menggunakan alat bantu pembelajaran akan membantu kelancaran pelaksanaan dalam proses pembelajaran. Menyanyi adalah bagian yang tidak terpisahkan dari dunia anak-anak (Purwanto, 2019; Santosa, 2019; Hayati, et al, 2019). Hal ini tidaklah mengherankan, karena lagu pada dasarnya adalah bentuk dari bahasa nada, yaitu bentuk dan tinggi rendahnya suara. Sedangkan, bahasa nada justru akan membawa mereka pada suasana riang, syahdu, sedih dan semangat.

Metode demonstrasi adalah metode panyajian pelajaran dengan memeragakan dan menunjukkan kepada siswa tetang suatu proses, situasi atau benda tertentu, baik sebenarnya atau hanya sekedar tiruan. Sudjana (2010) mengemukakan metode demonstrasi adalah suatu metode mengajar memperlihatkan bagaimana jalannya suatu proses terjadinya sesuatu. Oleh karena itu Metode Demonstrasi merupakan metode mengajar yang sangat efektif, sebab membantu para peserta didik untuk mencari jawaban dan usaha sendiri berdasarkan fakta yang dilihat. Menurut Sagala (2011) metode demonstrasi adalah pertunjukan tentang suatu proses ataubenda sampai pada penampilan tingkah laku yang dicontohkan agar dapat diketahui dan dipahami oleh peserta didik secara nyata, atau tiruan peragaan suatu proses dapat dilakukan oleh guru sendiri atau dibantu beberapa peserta didik, dapat pula dilakukan olehsekelompok peserta didik.

\section{Metode Penelitian}

Penelitian ini adalah penelitian tindakan kelas dengan pendekatan deskripif kualitatif .penelitian tindakan kelas ini menggunakan 2 siklus. Jenis penelitian ini merupakan jenis penelitian tindakan kelas dengan pendekatan deskriptif kualitatif. Setiap siklusnya terdiri dari perencanaan ,pelaksanaan, observasi,dan refleksi.Penelitian ini dilaksanakan pada anak kelompok B TK Kartini III Surakarta Tahun Pelajaran 2020/2021 semester genap yang berjumlah 20 anak dengan rincian terdiri dari 11 anak perempuan 9 anak perempuan,usia antara 5-6 Tahun.Sumber data penelitian ini berupa proses pembelajaran keterampilan menyayi dengan alat musik sederhana dengan satu guru kelompok B yang mengambil pembelajaran keterampilan menyanyi dikelompok B TK Kartini III Surakarta dengan alat musik sederhana menggunakan observasi individu ,kelompok, dokumentasi dan tes praktik menyayi dengan alat musik sederhana secara langsung hasil yang ditetapkan melalui penilaian peningkatan aspek perkembangan seni menyayi dengan alat musik sederhana.

Instrumen penelitian yang dilakukan berupa pengumpulan data observasi digunakan untuk proses pembelajaran keterampilan seni menyanyi dengan alat musik sederhana di kelas B selama observasi awal siklus1 dengan siklus 2 observasi menggunakan praktik secara langsung dengan cara kelompok atau bersama sama anak kelompok B siklus ke 2 dilakukan secara individu.Instrumen dokumentasi yang digunakan mengumpulkan informasi berupa dokumen terkait yang dilakukan. Intrumen angket digunakan untuk mengetahui respon siswa dan guru dalam pembelajaran.

\section{Hasil dan Pembahasan}

Dalam penilaian kemajuan anak pada setiap pengajaran musik, guru terlebih dahulu melihat tujuan yang hendak dicapai dalam kegiatan belajar mengajar tersebut. Berdasarkan tujuan itulah guru mengumpulkan keterangan yang diperlukan untuk menentukan tingkat pemahaman dan ketrampilan anak dalam bernyanyi atau memainkan alat musik, membandingkan hasil penilaian yang terdahulu dengan yang ada pada saat ini, kemudian membandingkan hasil penilaian saat ini dengan tujuan pengajaran musik yang dicapai oleh anak, mengamati secara konsisten kegiatan bernyanyi atau bermain alat musik tersebut sambil ikut sarta didalamnya.

Pada pra siklus hasil observasi menunjukan bahwa proses pembelajaran masih kurang maksimal. Masih ada anak yang mencapai BB atau Belum berkembang adalah 38 \%adalah 8 anak anak 
yang mencapai $\mathrm{MB}$ atau mulai berkembang $53 \%$ adalah 11 anak sedangkan anak yang mencai BSH( Berkembang sesuai. Harapan )tidak ada berdasarkan prasiklus maka guru merencanakan perbaikan pada pembelajaran siklus 1.

Proses penerapan kegiatan menyayi dengan alat music sederhana berlangsung dengan baik pada siklus 1. Proses penerapan kegiatan menyayi dengan alat music sederhana memiliki tiga tahap yaitu (1) persiapan yaitu peneliti menyiapkan RPPH dengan menggunakan metode demontrasi dan memperkenalkan media dan bahan; (2) pelaksanaan kegiatan pembelajaran dengan metode demontrasi ; dan (3) evaluasi. Dalam proses pembelajaran guru memberikan arahan kepada anak dalam menyiapkan, melaksanakan dan mengevaluasi kegiatan pembelajaran anak.

Pada kegiatan pembelajaran siklus 1 ini metode demonstrasi digunakan. Untuk meningkatkan motivasi anak, guru menggunaka metode demonstrasi yang lebih relevan,dimana pada siklus 1 guru mendemonstrasikan cara menyanyi serta menirukan guru sehingga anak paham apa yang harus dilakukan anak. Pembelajaran mengalami peningkatan signifikan melalui metode demonstrasi pada siklus 1 yaitu masih ada anak yang mencapai BB atau Belum berkembang adalah 2 orang atau $10 \%$ sedangkan 6 anak yang mencapai MB atau mulai berkembang $30 \%$ dan 4 anak yang mencapai berkembang sesuai harapan (BSH)atau 20\%, 2 anak atau $10 \%$ sedangkan anak yang berkembang sangat baik 10 anak atau $50 \%$.

Berdasarkan pada temuan siklus1 maka guru merencanakan perbaikan pada siklus kedua. Pada saat penelitian dilaksanakan nampak keaktifan anak semakin nyata hasil dari siklus 2 menunjukkan nilai Berkembang sangat Baik (BSB )dimana anak mencapai 80\% adalah 16 anak sedang yang mencapai Berkembang sesuai harapan ( BSH )20\% adalah 4 anak ditunjukkan pada table hasil belajar seni menyayi anak kelompok B terpenuhi.

Tabel 1. Hasil belajar siswa pada kegiatan pra siklus, siklus 1 dan siklus 2

\begin{tabular}{cccc}
\hline Nama sekolah & Prasiklus & Siklus 1 & Siklus 2 \\
\hline BB (Belum berkembang) & 8 & 2 & \\
MB (mulai berkembang & 11 & 6 & \\
BSH (Berkembang sesuai harapan ) & & 2 & 4 \\
BSB (Berkembang sangat baik) & & 10 & 16 \\
\hline
\end{tabular}

Dengan didapatnya hasil ini maka peneliti menghentikan penelitian pada siklus 2 karena pada siklus 2 dianggap sudah sesuai dengan kriteria keberhasilan tindakan yang yang dilakukan yaitu dengan relatif tingkat ketuntasan 75\%. Pembelajaran menggunakan metode demonstrasi dapat meningkatkan hasil belajar anak. Hal ini sesuai dengan pendapat Darmuki dkk. (2018) bahwa penggunan metode yang sesuai dapat meningkatkan hasil belajar peserta didik.

Berdasarkan kenyataan dan bukti diatas adat selamaa penelitian berlangsung keegiatan meningkatkan seni dengan kegiatan menyayi dengan alat music sederhana 16 anak benar benar meningkat .Sehingga dapat disimpulkan bahwa penggunaan alat music sederhana dapat menigkatkan kemampuan seni dalam kegiatan menyanyi kelompok B TK Kartini III Tahun ajara 2020/2021.

\section{Kesimpulan}

Berdasarkan hasil penelitian dan pembahasan di atas maka kesimpulan penelitian ini sebagai berikut. Penelitian kegiatan menyayi dengan alat music sederhana di TK Kartini III dilaksanakan dalam dua siklus.Setiap siklus terdiri atas 4 tahapan yaitu: perencanaan,,pelaksanaan ,observasi dan refleksi. Hasil dari kegiatan pembelajaran meningkatkan kemampuan seni kegiatan ketrampilan menyanyi menggunakan alat musik sederhana di kelompok B TK Kartini III. Pada pra siklus hasil observasi menunjukan bahwa proses pembelajaran masih kurang maksimal. .Masih ada anak yang mencapai BB atau Belum berkembang adalah $38 \%$ adalah 8 anak anak yang mencapai MB atau mulai berkembang 
$53 \%$ adalah 11anak sedangkan anak yang mencai $\mathrm{BSH}$ (Berkembang sesuai Harapan ).dimana pada siklus 1 guru mendemonstrasikan cara menyanyi serta menirukan guru sehingga anak paham apa yang harus dilakukan anak masih ada anak yang mencapai BB atau Belum berkembang adalah 2 orang atau $10 \%$ sedangkan 6 anak yang mencapai MB atau mulai berkembang $30 \%$ dan 4 anak yang mencapai berkembang sesuai harapan (BSH)atau 20\%, 2 anak atau $10 \%$ sedangkan anak yang berkembang sangat baik 10 anak atau $50 \%$. Pada saat penelitian dilaksanakan Nampak keaktifan anak semakin nyata hasil dar siklus 2 menunjukkan nilai Berkembang sangat Baik (BSB )dimana anak mencapai 83\% adalah 16 anak sedang yang mencapai Berkembang sesuai harapan ( BSH )17\% adalah 4 anak .Dari analisis tesebut dapat dikatakan tindakan perbaikan kegiatan pembelajaran yang penulis lakukan dapat meningkatkan kemampuan seni menyayi menggunakan alat musik sederhanadi kelompok B TK Kartini III dengan demikian proses perbaikan berhasil.

\section{Daftar Pustaka}

Asmawati Luluk. (2008). Pengelolaan Kegiatan Pengembangan Anak Usia Dini. Jakarta: Universitas Terbuka.

Departemen Pendidikan Nasional. (2002). Standar Kompetensi Guru TK/RA. Program Pendidikan D2 PGTK.

Darmuki, Agus. (2020). Upaya Meningkatkan Kemampuan Berbicara Mahasiswa Menggunakan Media Aplikasi Google Meet Berbasis Unggah Tugas Video Di Youtube Pada Masa Pandemi Covid-19. Jurnal Educatio FKIP UNMA, 6(2), 655-661.

Darmuki, A. \& Ahmad Hariyadi. (2019). Eksperimentasi Model Pembelajaran Jucama Ditinjau Dari Gaya Belajar Terhadap Prestasi Belajar Mahasiswa Mata Kuliah Berbicara Di Prodi PBSI IKIP PGRI Bojonegoro. Kredo. 3(1), 62-72.

Darmuki, A. \& Hidayati N.A. (2019). An Investigation of The Cooperative Learning Using Audio Visual Media in Speaking Skill Subject. ICSTI. 121-126.

Darmuki, A. \& Hidayati, N.A. (2019). Peningkatan Kemampuan Berbicara Menggunakan Metode Kooperatif Tipe NHT pada Mahasiswa Tingkat I-A Prodi PBSI IKIP PGRI Bojonegoro Tahun Akademik 2018/2019. Jurnal Pendidikan Edutama. Vol. 6(2), hlm 9-18.

Darmuki, A., Andayani, Joko Nurkamto, Kundharu Saddhono. (2017). Cooperative, Synectics, and CTL Learning Models Toward Speaking Ability Viewd from Students Motivation. Proceeding International Conference on Intellectuals'Global Responsibility (ASSEHR). Vol. 125, 75-79.

Darmuki, A., Andayani, Joko Nurkamto, Kundharu Saddhono. (2017). Evaluating InformationProcessing-Based Learning Cooperative Model on Speaking Skill Course. Journal of Language Teaching and Reasearch. 8(1) pp. 44-51.

Darmuki, A., Andayani, Joko Nurkamto, Kundharu Saddhono. (2018). The Development and Evaluation of Speaking Learning Model by Cooperative Approach. International Journal of Instruction. 11(2), 115-128.

Darmuki, A., Ahmad Hariyadi, Nur Alfin Hidayati. (2020). Peningkatan Minat dan Hasil Belajar Keterampilan Berbicara Menggunakan Metode Mind Map pada Mahasiswa Kelas IA PBSI IKIP PGRI Bojonegoro Tahun Akademik 2019/2020. Kredo.

Depdiknas. (2005). Standar Kompetensi Mata Pelajaran Kesenian. Jakarta: Pusat Kurikulum, Balitbang Depdiknas.

Gunarti Winda. (2008). Metode Pengembangan Perilaku dan Kemampuan Dasar. Anak Usia Dini. Jakarta: Universitas Terbuka.

Hayati, N., Fatimaningrum, A. S., \& Wulandari, R. (2019). Kegiatan Menyanyi dalam Pembelajaran Anak Usia Dini. Jurnal Pendidikan Anak, 8(2), 116-125. 
Hidayati, N. A., \& Darmuki, A. (2021). Penerapan Model Auditory Intellectually Repetition (AIR) untuk Meningkatkan Kemampuan Berbicara Pada Mahasiswa.Jurnal Educatio FKIP UNMA, 7(1), 252-259.

Lwin, May dkk. (2008). Cara Mengembangkan Berbagai Komponen Kecerdasan. Yogyakarta: PT. INDEKS

Maseso Iksan. (2007). Evaluasi Pembelajaran TK. Jakarta: Universitas Terbuka.

Purwanto, S. (2019). Penanaman Nilai Karakter pada Anak Usia Dini melalui Pembelajaran Berbasis Musik dan Lagu Model. ThufuL A: Jurnal Inovasi Pendidikan Guru Raudhatul Athfal, 3(1), 1-15.

Santosa, D. (2019). Urgensi Pembelajaran Musik Bagi Anak Usia Dini. Pawiyatan, 26(01), 78-88.

Sousa, David A. (2012). Bagaimana Otak Belajar. Jakarta : PT. Indeks.

Suardika, I. K. (2018). Mengembangkan Kecerdasan Musikal Anak dalam Kegiatan Bernyanyi Lagu Daerah Tolaki pada Kelompok B Tk Kuncup Pertiwi Kendari. Jurnal Pembelajaran Seni dan Budaya, 3(1), 286836.

Widia Pakerti, dkk. (2015). Metode Pengembangan Seni. Jakarta: Universitas Terbuka 